\title{
ENTREVISTA COM CYRO CORRÊA LYRA
}

Flávia Mattos

Universidade Federal do Rio de Janeiro, Brasil
DOI: https://doi.org/10.18472/cvt.20n2.2020.1866 Redalyc: http://www.redalyc.org/articulo.oa? $\mathrm{id}=115464354008$

A nova fase do Caderno Virtual de Turismo - Tempespaço (CVT) reafirma a abertura ao diálogo e as colaborações em rede, nacionais e internacionais. Seguindo esse fluxo começamos nessa edição uma seção da revista dedicada a entrevistas com personalidades plurais da cena contemporânea.

Queremos com isso marcar a importância da escuta ativa, das interações e interlocuções que atravessam os anos de trabalho de seus editores, na busca de sentidos que ultrapassam o mero aspecto formal de uma entrevista, ou dos discursos em geral. A presente entrevista inaugura uma série que se perpetua em números futuros e pretende ser exercício da palavra ouvida, do "lugar de escuta".

Nosso primeiro entrevistado é Cyro Corrêa Lyra. As razões dessa escolha não são casuais. Cyro é um participante ativo da construção da política de preservação do patrimônio cultural do Brasil. Uma memória viva de fases e influências que marcaram mais de meio século de intervenções no patrimônio edificado brasileiro.

Arquiteto, nascido em Petrópolis, tendo vivido grande parte de sua vida em Curitiba e no Rio de Janeiro, Cyro conviveu com figuras ilustres e formou gerações de alunos. Guarda a autoridade e o carisma dos muitos encontros e trocas que realizou e conquistou em sua vasta trajetória profissional e pessoal em prol do patrimônio. Com vivência ímpar em diversos projetos e obras de restauração, teórica e prática, tem destacado, ao longo dos seus trabalhos, como a questão do uso do patrimônio edificado está intrinsecamente ligado à possibilidade de sua preservação.

As conversas que resultaram na entrevista foram realizadas entre os meses de agosto e setembro de 2020, em meio a pandemia pelo novo coronavírus SARS-CoV2 e realizadas por compartilhamento de arquivo e vídeo-chamadas. Uma adaptação interativa no período de isolamento social. Entre vivências pretéritas e a sensibilidade para os desafios contemporâneos, seguimos com Cyro...

\section{Flávia Mattos}

\section{Entrevista com Cyro Corrêa Lyra}

\author{
Entrevistadora Flávia Mattos
}

Setembro/2020

\section{Sua trajetória de vida profissional confunde-se com a história de preservação do patrimônio do Brasil. Como aconteceu esse entrelaçamento? E quais suas principais memórias desse percurso?}

Esse entrelaçamento tem início ainda na faculdade quando fiz estágio no DPHAN (Departamento do Patrimônio Histórico e Artístico Nacional) dirigido ainda por Rodrigo Melo Franco de Andrade. Fui fazer esse estágio por influência dos professores da disciplina de Arquitetura no Brasil: Paulo Santos e Augusto Silva Telles. Isso se deu no ano de 1961 quando cursava o quarto ano da faculdade (na época Faculdade Nacional de Arquitetura). Acompanhava o Augusto na sua atividade de fiscalização de obras de restauração 
aqui no Estado do Rio. Entusiasmei-me não só com a história da arquitetura brasileira - assunto daquela disciplina - como também com aquela atividade de restauração. Naqueles dois últimos anos de faculdade (1961 e 62) tive a oportunidade de conhecer o Diretor do DPHAN, Rodrigo Mello Franco de Andrade e seus assessores, pessoas extraordinárias, como Renato Soeiro, Lucio Costa, Edson Motta, Paulo Thedim Barreto, entre outros. Quando me formei falei com Augusto que gostaria de trabalhar na área, mas ele me disse que o DPHAN não tinha como contratar pessoal pois, ele mesmo, não era funcionário, recebendo por verbas de obras, se não me falha a memória. Foi quando ele me disse que no Paraná tinham criado um Curso de Arquitetura e o tinham convidado para lecionar, mas ele não pretendia sair do Rio. Por que eu não tentava já que meu irmão tinha casado com uma paranaense e se mudado para Curitiba? Já tinha estado lá por ocasião do seu casamento e sabia que aquele estado estava em grande desenvolvimento. Ainda no quinto ano da faculdade tive a oportunidade de fazer um levantamento de uma igreja em Paranaguá depois de uma troca de correspondência entre o Departamento do Patrimônio Histórico e Artístico do Estado do Paraná e o DPHAN. Esse levantamento serviu para eu estreitar laços com o pessoal desse setor naquele Estado. Logo depois de ter sido formado arquiteto decidi tentar o ingresso como professor do recém criado Curso de Arquitetura do Centro Politécnico da UFPR. Tive sorte pois naquele momento, 1963, o curso estava no seu segundo ano de funcionamento e não tinha ainda professor contratado para Arquitetura no Brasil. Meu currículo era paupérrimo, mas tinha uma joia: uma carta de Rodrigo Mello Franco atestando que tinha estagiado no DPHAN. Fui aceito e naquele ano de 1963 teve início minha carreira como professor. Quatro anos depois o pessoal do Departamento do Patrimônio Histórico e Artístico do Estado do Paraná me contactou para saber se eu tinha interesse em coordenar a restauração da igreja de São Benedito em Paranaguá. Meu nome tinha sido referenciado pelo DPHAN o que era um aval para essa missão. Foi minha primeira obra de restauração, realizada no ano de 1968. Durante esse trabalho mantinha correspondência com Augusto para troca de ideias e contactei o restaurador do DPHAN, Edison Motta para saber se poderiam ser restauradas algumas imagens no atelier de restauração que ele dirigia no DPHAN. Foi assim que eu transportei na minha caminhonete as imagens de N. Senhora, Santa Luzia, Santa Efigênia e não sei se mais alguma para o Rio onde as entreguei ao Edison. Na obra de São Benedito a restauração dos altares estava sendo realizada por uma restauradora catarinense, Beatriz Pelizetti, que tinha sido estagiária do Edson. Na cerimônia de reabertura da igreja, vieram do Rio o Rodrigo que não era mais diretor (ele dirigiu o órgão de 1937 a 1967) e o Renato Soeiro que tinha assumido a direção após a aposentadoria do Rodrigo. Uma triste informação é que poucos anos depois aquelas imagens, magnificamente restauradas pelo Edson e sua equipe, foram roubadas...

Um ano depois fui chamado a São Paulo para conversar com o chefe do $4^{\circ}$ Distrito do DPHAN, responsável pelos estados de SP, PR, SC e RS, arquiteto Luís Saia. Ele me propôs a criação de uma empresa para executar obras nos 3 estados do sul. Assim surgiu a empresa Aresta, arquitetura e restauro que dirigi até 1982. De 1969 a 1982 coordenei muitas obras para o DPHAN que em 1970 passou a se chamar de IPHAN. Também neste período coordenei restaurações executadas por outras empresas em Curitiba. De 1971 a 73 dirigi o Departamento do Patrimônio Histórico e Artístico do Estado do Paraná, período em que tive que me afastar da Aresta. Nesses três anos de direção conduzi a restauração do prédio da antiga Prefeitura Municipal de Curitiba - convertida em Museu Paranaense - e da Casa Romário Martins, também naquela cidade, adaptada para Centro cultural. Ao sair do cargo no Estado, voltei à Aresta, retomando as obras no sul.

Mantendo contato por correspondência com o Augusto, soube da existência de um curso de especialização ligado a Unesco, em Roma. Candidatei-me e fiz o curso em 1976. Como ia anualmente ao Rio, principalmente no verão levando minha família para ali passar as férias, o contato com o IPHAN continuava, não só com o Augusto como também com o Diretor, Renato Soeiro. Desse contato saiu um convite para eu lecionar no Curso de Especialização em Conservação e Restauração que ia ocorrer naquele ano em Recife, fruto de um convênio do IPHAN com a UFPE. Lecionei então lá na disciplina de projeto de restauro. Dois anos depois fui fazer o mesmo trabalho no Curso semelhante em Belo Horizonte. E depois, em 1982, em 
Salvador no curso denominado de CECRE (Curso de Especialização em Conservação e Restauração). A partir de então a cada dois anos ia para Salvador para orientar os alunos, arquitetos, em projetos de restauro.

Em 1980 esteve em Curitiba o novo dirigente do IPHAN, Aloisio Magalhães. Eu e José La Pastina Filho (ex-aluno e meu companheiro na condução das obras da Aresta) acompanhamos Aloísio numa visita a um antigo moinho de mate, que estava para ser restaurado por nós. Um ano depois fui convidado a ingressar na Fundação Pró-Memória. Expus a notícia à minha família para saber se era do agrado de todos ir para Brasília. A ideia foi aceita, mas, um ano depois, com o falecimento de Aloísio, Augusto propôs que não fossemos para Brasília, mas, sim, para o Rio. Assim transferi a firma para os arquitetos que comigo trabalhavam, arrumei as malas e voltei em 1983 para o Rio, para a Pró-Memória, onde passei a trabalhar no Departamento de Tombamento e Conservação, dirigido pelo Augusto Silva Telles. Naquele mesmo ano o sucessor de Aloisio, Marcos Vilaça, me contactou propondo que eu com minha experiência de obra, assessorasse o Superintendente do IPHAN no Rio, Glauco Campello, na restauração do antigo Paço Imperial. Foi uma experiência ótima. Primeiro, porque pela primeira vez trabalhei com uma equipe multidisciplinar que incluía arqueólogos, historiadores e engenheiros. E, depois, porque foi uma obra polêmica pois parte dos colegas do IPHAN discordavam do partido que adotamos de retomar a volumetria original eliminando os acréscimos feitos pela Empresa de Correios e Telégrafos durante o período em que ocupou a edificação.

Foram muito importantes como referências os três primeiros dirigentes do Iphan, inclusive, por se tratarem de pessoas que contribuíram para moldar a instituição. e com os quais tive a felicidade de conviver. O primeiro, Rodrigo Mello Franco de Andrade, dirigiu a instituição por trinta anos (1937/1967), período que costumamos denominar de "fase heroica". Ele construiu o órgão. Como um bom mineiro, foi um grande político, no sentido de conduzir a instituição em uma época difícil como foi o Estado Novo. Soube reunir o melhor da intelectualidade da época: de Mario de Andrade a Lucio Costa, Oscar Niemeyer, Carlos Drumond de Andrade. Montou uma equipe de alto nível que incluía Judite Martins, Ligia Martins Costa, José de Souza Reis, Edison Motta, Paulo Thedim Barreto e muitos outros. As perdas que houve, como a demolição igreja de São Pedro dos Clérigos (para abertura da Avenida, hoje Presidente Vargas) - uma das mais ricas obras barrocas do Brasil - para ocorrer foi necessário que Getúlio Vargas assinasse um decreto criando a "figura" do "destombamento". Esse instrumento foi usado muito pouco. Durante o governo militar, por exemplo, nunca foi acionado, nem nos anos seguintes, felizmente. O braço direito de Rodrigo, Renato Soeiro, foi seu sucessor. Arquiteto, de origem paraense, mas formado no Rio, dirigiu o órgão de 1967 a 1980 . Modernizou a instituição. Preocupado com os conjuntos urbanos criou um programa de investimentos para as cidades tombadas do Nordeste: Programa de Reconstrução das cidades históricas do Nordeste. Conhecido pela sigla PCH, devido ao seu sucesso, foi estendido a outras regióes. Nesse Programa, era dada uma atenção especial à potencialidade das cidades históricas para o desenvolvimento do turismo cultural. Em 1970, o Ministério da Educação atendeu proposta de Soeiro de convocar governadores e prefeitos para colaborarem com o IPHAN (o DPHAN - Departamento do Patrimônio Histórico e Artístico Nacional, torna-se Instituto em 1970).É justamente nesse ano de 1970 que é realizado em Brasília um primeiro encontro do IPHAN com governantes de todos os estados e de muitos municípios, sendo suas resoluções reunidas na "Carta de Brasília". Um ano depois ocorre um segundo encontro, em Salvador, do qual participei. Deve-se também a Soeiro a criação de cursos de especialização em conservação e restauro, através de convênios com universidades. $O$ primeiro foi em São Paulo (1974) com a USP. Dois anos depois ocorreu o de Recife com a UFPE. Seguiu-se em 1978 o de Belo Horizonte, com a UFMG e a partir de 1981, consolidou-se em Salvador, com o nome de CECRE.

Em 1980 o IPHAN passa à direção do pernambucano Aloísio Magalhães, artista plástico e designer. Embora sua gestão tenha sido muito curta pois ele faleceu em 1982, ela foi marcante, no sentido de uma abertura da casa. Não só através de práticas de discussão do patrimônio com as comunidades envolvidas como também para um reconhecimento mais efetivo das manifestações culturais e, por extensão, do patrimônio imaterial. 


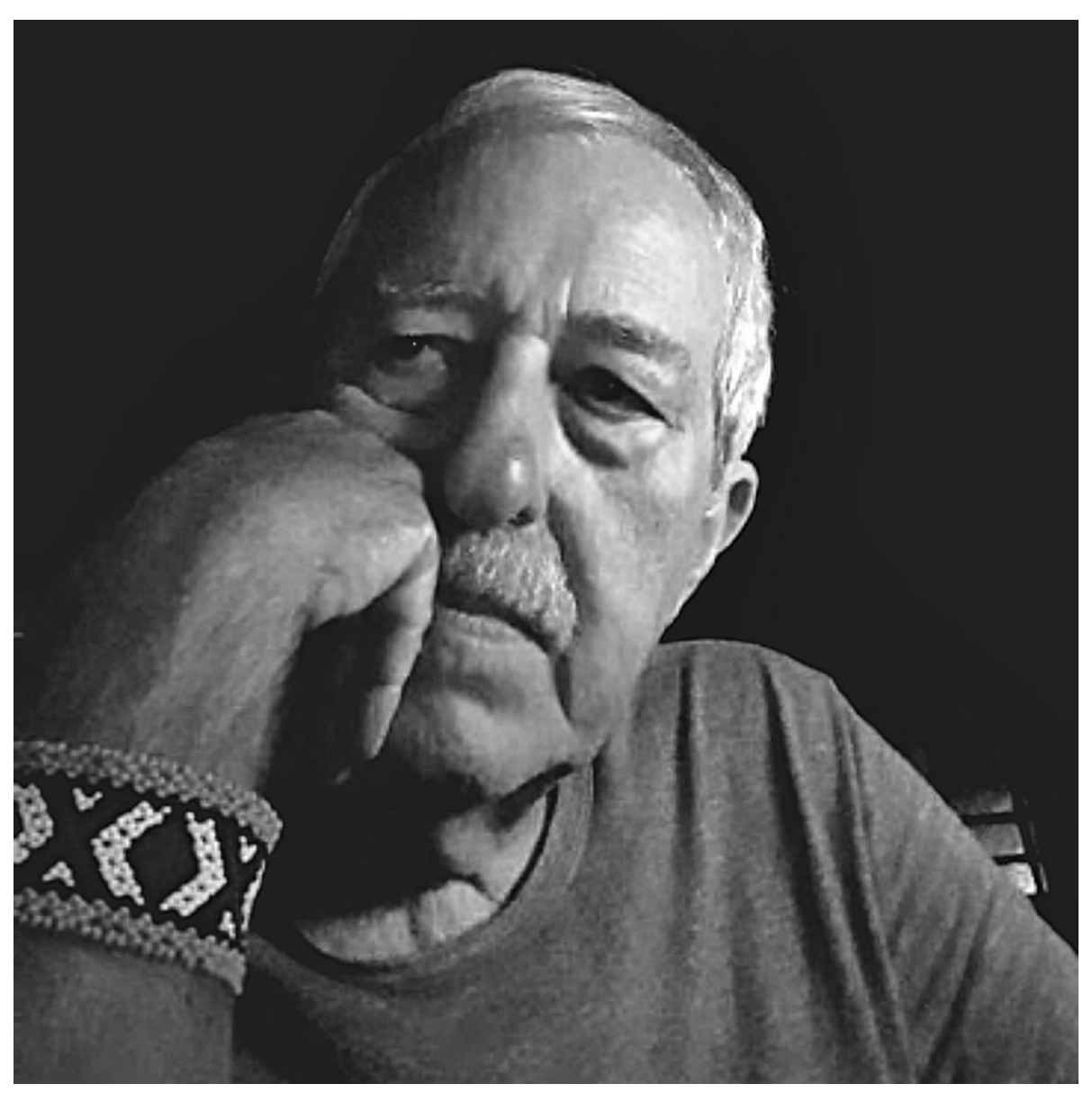

Cyro Corrêa Lyra / Foto: Flávia Mattos

\section{Quem foram os seus elos de referências e quais ensinamentos inspiraram sua vida profissional como arquiteto, como gestor público e como professor?}

$\mathrm{Na}$ minha formação como arquiteto dois professores foram fundamentais, na medida em que conduzi minha vida para uma carreira paralela - restaurador e professor. Foram eles, o Paulo Santos e o Augusto Silva Telles. Paulo Santos, arquiteto, era o catedrático da disciplina responsável pela disciplina Arquitetura no Brasil, cuja matéria significava história da arquitetura brasileira. Silva Telles era o seu auxiliar. Dividiam a matéria, Paulo Santos falava do moderno e Augusto do passado, isto é, do colonial ao final do Império. Na atividade de professor, as aulas do Silva Telles foram referência para mim, inclusive o programa da disciplina que montei foi baseada no programa organizado por ele para a UFRJ.

No dia a dia de trabalho no Sul o contato frequente com o Luís Saia, arquiteto, formado pela USP e funcionário do DPHAN. é claro, me marcou, embora fosse uma ligação esporádica, já que ele vivia em São Paulo, mas era a ele que eu tinha que prestar contas das restaurações contratadas pelo IPHAN. Além disso eu o acompanhei em diversas viagens a Santa Catarina e ao Rio Grande do Sul. Acredito que nos muitos diálogos que travamos eu tenha aprendido muito, inclusive, porque ele era muito culto e um grande pesquisador da nossa arquitetura pretérita. Minha estada no Sul foi muito marcada também pelas ações desenvolvidas em Curitiba, primeiro no período em que trabalhei no IPPUC - Instituto de Pesquisa e Planejamento Urbano de Curitiba, durante o qual, coordenei a implantação do Centro Histórico. E depois realizando diversas restaurações nessa área central, não só para a Prefeitura (obra da Casa Romário Martins e da Fundação 
Cultural de Curitiba) mas também para particulares como o restauro de uma casa para sede do Instituto Goethe e mesmo para entidades como as restauraçóes da igreja da Ordem e da Catedral.

3. Em "Casa vazia, ruina anuncia" - você traz à tona a importância do uso do patrimônio em contraposição a ideia de "preservar por preservar". Vencida essa primeira compreensão "paradigmática" é necessário refletir sobre usos compativeis e situados (em diferentes casos) e os diversos interesses associados na apropriação do patrimônio. Como construir sinergias para a preservação e garantir equilibrio nessas relações nem sempre harmônicas? Onde estão os principais gargalos no Brasil?

Cada obra de arquitetura é marcada pela sua função, ou seja, ela é vocacionada. Um convento como um quartel está na mesma família de uma hospedaria, ou seja, são espaços que foram concebidos para abrigar muitas pessoas. Isso explica como dois dos antigos conventos carmelitas baianos são hoje hotéis. É claro que obras cujas finalidades desapareceram se constituem sempre em reutilizações mais difíceis. Os fortes são um exemplo disso. Seus quartéis podem ser revitalizados com funções de moradia coletiva. Mas como reutilizar casamatas e paióis de pólvora? A tendência é torná-los apenas locais de visitação, ou seja, de uso transitório, não permanente. A arquitetura não deve ser restaurada da mesma forma que a arte plástica, exatamente devido ao seu caráter utilitário. Se a destinação de uma obra de arquitetura for de contemplação apenas, aí sim, podemos restaurá-la à maneira da arte plástica. Exemplo: a "Casa da Hera", situada em Vassouras, no Estado do Rio de Janeiro. Ela pertenceu à D. Eufrásia Teixeira Leite e foi restaurada de forma a expor como ela era quando foi construída. Ou seja, seu uso se assemelha ao de uma peça museológica, não só pela arquitetura, mas, principalmente, pelo conteúdo: móveis, utensílios domésticos, vestidos, datados da época em que a casa era uma residência de uma mulher culta que frequentava a Corte Imperial.

A revitalização de uma edificação antiga depende da viabilidade econômica do projeto que resulta de muitos fatores, como a localização. Fazer de um convento antigo desativado um hotel depende em primeiro lugar da potencialidade turística do local. $\mathrm{O}$ uso exclusivamente museológico, por exemplo, é sempre, deficitário. Nem o Museu do Louvre é sustentado pela arrecadação da bilheteria.

4. A propagação da Covid-19 em escala planetária na atualidade provocou ponto de inflexão nas relaçôes humanas, sociais, politicas, econômicas de forma sem precedentes nos últimos 100 anos. Quais as consequências na dinâmica das cidades?

Uma das consequências desse período de confinamento das pessoas é o esvaziamento dos escritórios situados nos centros urbanos e a descoberta da potencialidade do trabalho a distância. Muitas empresas vão se desfazer dos grandes espaços que mantinham. Vai ser consolidado o uso híbrido - alguns terão que trabalhar in loco e outros poderão desenvolver suas atividades a distância. Isso vai criar a possibilidade de reciclagem de prédios originalmente de uso exclusivo comercial para o uso residencial. É a oportunidade de revitalização dos centros urbanos que, diferentemente de hoje, deixarão de ser esvaziados nos fins de semana. Será uma redescoberta do centro da cidade. Isso dependerá, é claro, do apoio municipal através de incentivos.

5. O Brasil, sob a coordenação do Iphan, vem trabalhando desde 2017 no processo de construção da candidatura a Patrimônio Mundial do bem seriado "Conjunto de Fortificaçôes do Brasil", envolvendo 19 fortificações (componentes), que se encontram sob diferentes administrações, em 


\section{Estados brasileiros. O que você tem a dizer sobre essa iniciativa brasileira e quais os principais desafios?}

A iniciativa do ponto de vista teórico é muito boa, no meu entender. Já que nossos fortes, individualmente, não possuem valores arquitetônicos excepcionais, comparados com os europeus (os da França, por exemplo) e os da América Central. Mas sua importância como conjunto, sim, na medida em que contribuíram decisivamente para estender as fronteiras de modo a se formar uma nação de dimensões continentais e marcada pela diversidade geográfica. Entretanto essa diversidade se constitui, em termos práticos, em uma grande dificuldade a ser enfrentada, dada as dimensões do Brasil. Há diferentes gestores e os fortes encontram-se em municípios com condições diversas. Além disso há uma questão central que afeta esse tipo de monumento: o distanciamento da população local em relação ao monumento. A noção de pertencimento em relação a fortificações ocupadas com unidades militares não ocorria porque, por uma questão de segurança elas se constituíam em locais reservados aos militares. Mesmo levando em conta que se tornaram locais visitáveis atendendo a preocupações das autoridades militares numa maior integração das guarnições com a população local. Mas, hoje, a noção de pertencimento varia. Há fortes que estão integrados à cidade, principalmente aqueles que não abrigam guarnições militares e são mantidos pelo município, pelo Iphan e pelas universidades. É necessário reconhecer, porém, que as autoridades militares têm, de um modo geral, trabalhado no sentido de integração com as comunidades locais das fortificações sob sua administração. Principalmente nos fortes cuja destinação de uso passou a ser exclusivamente cultural, como os de Santo Antônio da Barra, o São Diogo e o Santa Maria, situados em Salvador.

O título almejado por essa candidatura é importante para o Brasil por tratar-se do reconhecimento do papel desempenhado por um conjunto de construções erguidas em diferentes pontos estratégicos para a finalidade castrense. Além disso, nesse momento em que se comemoram oito décadas de ação preservacionista por parte do poder público, é significativo o reconhecimento de valor universal para uma série de bens cujo valoração está presente desde os primeiros dias da instituição federal de preservação. De 1938 a 1950 um número considerável de fortificações, situadas do sul ao norte, tem seu valor reconhecido, sendo inscritas no Livro do Tombo Histórico do SPHAN. Das 19 fortificações que integram a candidatura, doze foram tombados nos três primeiros anos de implantação do SPHAN e os demais em anos posteriores. São elas, com seus respectivos anos de tombamento: Forte de São Tiago das Cinco Pontas (1938); Forte de São João Batista do Brum (1938); Forte de Santa Cruz de Itamaracá (1938); Fortaleza de Santo Antônio de Ratones (1938); Fortaleza de Santa Cruz de Anhatomirim (1938); Fortaleza Santa Catarina (1938); Forte de Santo Antônio da Barra (1938); Forte de Santa Maria (1938); Forte São Marcelo (1938); o portão da Fortaleza de São João (1938); Fortaleza de Santa Cruz da Barra (1939); Forte de São João de Bertioga (1940); Forte dos Reis Magos (1949); Fortaleza de São José de Macapá (1950); Real Forte Príncipe da Beira (1950); Forte de N.Sra. de Monte Serrat (1957); Forte de São Diogo (1959); Fortaleza de Santo Amaro da Barra Grande (1964); e Forte de Coimbra (1974). O reconhecimento deles como integrantes de um conjunto de valor universal vai contribuir para melhoria do seu desempenho como bens culturais pela repercussão desse feito na população local.

\section{Em 2016 o governo português lançou um programa com o objetivo de promover a requalificação e o aproveitamento turístico de imóveis públicos com valor patrimonial, que se encontravam arruinados ou bastante degradados, de modo a convertê-los em ativos econômicos geradores de}


emprego e riqueza, com incorporação de aspectos sociais, respeito às identidades: o Revive. No Brasil almeja-se construir experiência análoga. O que se deve refletir para o Revive Brasileiro?

O reconhecimento de que o poder público não tem condições de conservar sozinho os imóveis tombados, justifica a procura de fórmulas de atuação compartilhada com a iniciativa privada. Foi nessa linha que se forjou o Programa Revive em Portugal que vem apresentando alguns bons resultados na revitalização de alguns bens de valor patrimonial. Vale a pena tentar um projeto semelhante no Brasil, mas reconhecendo tratar-se de realidade completamente diversa. Não temos conventos e quartéis do porte dos que existem em Portugal. Os quatro monumentos escolhidos possuem algumas condições para despertar interesse por parte de empresários. $\mathrm{O}$ forte da ilha de Fernando de Noronha me parece o que reúne boas qualidades para hotel além de se situar em um local paradisíaco incluído nos roteiros turísticos. Não é o que acontece com o Santa Catarina, em Cabedelo, por causa de um entorno problemático. Os dois outros tem algumas condições favoráveis. O forte Orange pela localização magnífica e a Fazenda Pau D’Alho por sua disposição arquitetônica típica de uma antiga fazenda cafeeira - potencialmente um hotel-fazenda.

É importante lembrar que na concessão à empresa privada deve ficar garantido o acesso do público ao monumento para conhecer seus valores históricos e/ou artísticos que justificaram sua preservação. Por outro lado, tem o empresário o direito de vedar o acesso a determinadas áreas como, por exemplo, no caso de hotéis, os espaços destinados a hospedagem.

Finalmente nunca é tarde lembrar que a intervenção em bens culturais protegidos por lei deve seguir preceitos ditados por diversos documentos elaborados por especialistas e aprovados em reunióes internacionais, notadamente aquelas organizadas pelo ICOMOS (Conselho Internacional de Monumentos e Sítios).

\section{O Caderno Virtual de Turismo - Tempespaço (CVT) está voltado para reflexão do patrimônio numa perspectiva ampla. Como membro do Conselho editorial do CVT, quais os temas de pesquisa você considera importantes de serem revisitados e quais os novos campos de estudos se abrem no cenário contemporâneo e merecem atenção?}

Em primeiro lugar, a discussão sobre o futuro de monumentos que perderam a sua função. Incluem-se nessa categoria, fortificações, conventos de certas ordens religiosas, sedes de fazendas de áreas em processo de urbanização. Outro tema que considero pertinente é a conservação de ruínas. E um terceiro e oportuno assunto é a revitalização das áreas urbanas economicamente esvaziadas com a reutilização de edificações ociosas para o uso habitacional. Finalmente considero oportuna a discussão sobre o desafio da conservação e manutenção dos bens protegidos. A maioria dos bens edificados volta a se degradar pouco tempo depois de passar por uma custosa e minuciosa restauração. Isso ocorre frequentemente com as igrejas que se constituem nos mais importantes monumentos do ponto de vista do valor artístico.

\section{Quais as sugestões de leituras você indicaria para aqueles que desejam conbecer mais sobre $o$ patrimônio cultural desde a perspectiva da sua atuação profissional?}

Para conhecer o patrimônio cultural brasileiro edificado, as leituras imprescindíveis ainda são aquelas em grande parte produzidas pelos precursores: os escritos de Germain Bazin (arte religiosa), Lucio Costa (arte jesuítica), do Luís Saia (patrimônio paulista), do Thedim Barreto (casas de câmara e cadeia), Sylvio de Vasconcellos (patrimônio mineiro), entre outros. Somam-se a eles os trabalhos produzidos por pesquisadores mais recentes como Benedito Toledo e Myriam Ribeiro (arte religiosa), Mário Mendonça e Victor Hugo 
Mori (arquitetura militar), Jussara Derenji (arquitetura de ferro) e Nestor Goulart Reis (arquitetura civil). Essas indicações são restritas à parcela do patrimônio cultural no qual atuo. Vale observar a existência de uma quantidade razoável e promissora de novos pesquisadores que escolheram áreas do campo patrimonial para suas teses, envolvendo não só o edificado, mas, também, outras vertentes: no campo do material, o urbanismo e no do imaterial, as manifestações.

\section{O que desejar para o futuro das politicas de preservação do patrimônio cultural no Brasil?}

O sucesso da preservação do patrimônio depende principalmente de um esforço de divulgação e conscientização da população. O patrimônio só é preservado de fato quando seu valor é de fato reconhecido e compreendido pelas pessoas que com ele convivem. A noção de pertencimento pressupõe o conhecimento e a sensibilização, que deveriam começar na infância. Nos dias de hoje um dos adversários é o celular, aparelho que se tornou o companheiro permanente de todas as pessoas. A possibilidade de informação imediata que ele permite desestimula a descoberta gradativa. $\mathrm{E}$ a verdade é que a apropriação do patrimônio é um processo lento e gradativo. A preservação do patrimônio requer o desenvolvimento de um processo educativo que estimule a descoberta dos valores que não são apropriáveis de imediato.

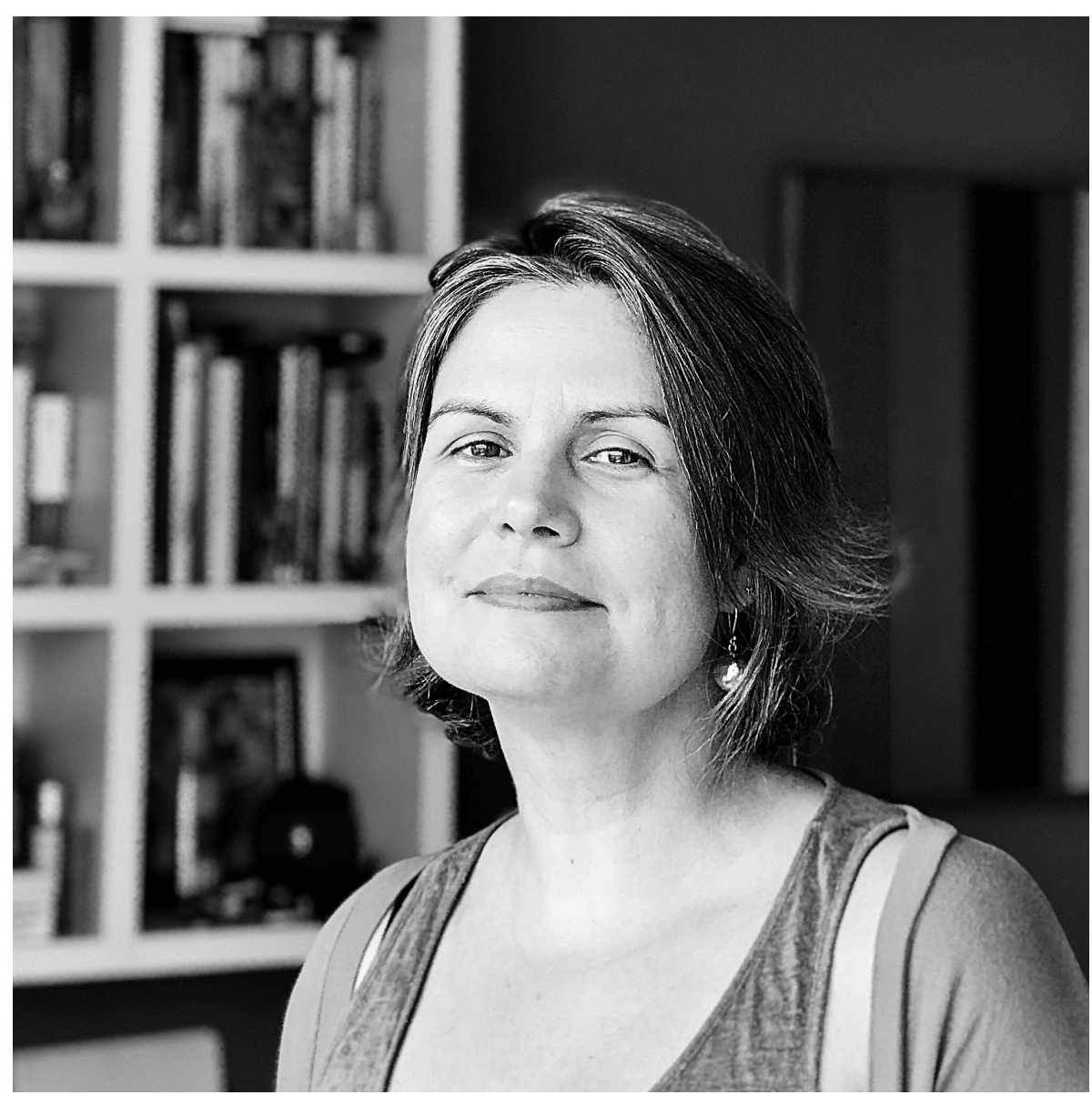

Flávia Mattos é psicóloga, doutora em Engenharia de Produção pela COPPE/ UFRJ e editora científica do Caderno Virtual de Turismo - Tempespaço (CVT). 